\title{
Survey and Detection of 'Candidatus Liberibacter asiaticus' in a Citrus Nursery Facility in South Texas
}

\begin{abstract}
Olufemi J. Alabi, Department of Plant Pathology \& Microbiology, Texas A\&M AgriLife Research and Extension Center, Weslaco 78596; Madhurababu Kunta, Texas A\&M University, Kingsville Citrus Center, Weslaco 78599; Jon Dale, Texas Citrus Mutual, 901 Business Park Drive \#400, Mission 78572; and Mamoudou Sétamou, Texas A\&M University, Kingsville Citrus Center, Weslaco 78599
\end{abstract}

Accepted for publication 27 August 2014. Published 15 December 2014.

\section{ABSTRACT}

Alabi, O. J., Kunta, M., Dale, J., and Sétamou, M. 2014. Survey and detection of 'Candidatus Liberibacter asiaticus' in a citrus nursery facility in South Texas. Plant Health Progress doi:10.1094/PHP-RS-14-0028.

Huanglongbing (HLB) disease, associated with 'Candidatus Liberibacter asiaticus' (CLas), is primarily spread via infected citrus nursery trees and by infective Asian citrus psyllid, the insect vector. Recently, the Texas Department of Agriculture initiated regulations requiring commercial and retail citrus nurseries in Texas to transition from traditional open-field to enclosed facilities with insect-resistant screens to mitigate the risk of nurseries serving as sources of CLas. Although several nursery production facilities have adopted this regulation, non-enclosed nurseries persist and pose a significant threat to the citrus industry as potential sources of CLas. A systematic survey for

\section{INTRODUCTION}

Huanglongbing (HLB) or citrus greening is currently considered the most devastating disease of citrus globally (5). The disease affects all members of the Rutaceae and can cause premature fruit drop, gradual decline, and eventually death of affected trees. In commonly cultivated citrus varieties such as sweet oranges, grapefruits, limes, and lemons, HLB produces a variety of symptoms including asymmetric blotchy mottling, corky and raised veins, and pronounced vein chlorosis on mature leaves of affected plants. Such symptoms are often restricted to sectors of affected trees and may be apparent only in advanced stages of the disease, by which time such trees may have served as sources of inoculum for spread to other trees. Hence, asymptomatic spread of HLB could occur via transmission by the Asian citrus psyllid (ACP; Diaphorina citri Kuwayama) insect vector, owing to the prolonged incubation of the disease in infected plants (5).

Currently, three related but distinct phloem-inhabiting bacterialike agents have been associated with HLB globally: 'Candidatus Liberibacter asiaticus' (2,3,13); ' $C a$. L. africanus' (4,12); and ' $C a$. L. americanus' (13). 'Ca. L. asiaticus' (CLas) and CLam have been reported from Texas (9), with the former being the predominant liberibacter while the latter has been found only in one sample of infective psyllids encountered at a location in the Lower Rio Grande Valley (LRGV) of South Texas (http://southwestfarmpress.com/orchard-crops/new-strain-hlbdisease-found-south-texas-citrus-grove?page=1). In Texas, CLas

Corresponding author: Olufemi J. Alabi. Email: alabi@tamu.edu

doi:10.1094/PHP-RS-14-0028

(c) 2014 The American Phytopathological Society
HLB was embarked on in a semi-open nursery facility in South Texas in April 2014. Leaf tissue samples taken from 94 trees representing 5\% of the total number of potted trees in the nursery were tested for CLas by quantitative and conventional PCR assays. Of 94 trees tested, 3.2\% (3 trees) were positive for CLas by both assays. The presence of CLas in the PCR-positive samples was confirmed by multi-locus sequence analyses. The results represent the first report of HLB in a nursery facility in Texas, and underscore the need for more intensive surveillance for HLB in citrus nursery stock as an integral component of HLB mitigation efforts in Texas.

has been detected in several citrus and ACP samples obtained from over 200 groves and residential sites across the LRGV, prompting a recent declaration of the Hildago, Cameron, and Harris counties as state and federal quarantine areas for HLB. The United States Department of Agriculture Animal and Plant Health Inspection Service (USDA-APHIS) and relevant state and industry entities are continuing to survey for the disease across Texas as part of ongoing HLB mitigation efforts.

The National Research Council of the United States National Academy of Sciences (USNAS) recommended a three-pronged approach to HLB disease management, including removal of infected trees, effective ACP control, and planting of "clean" nursery trees (11). Contaminated nursery trees are of particularly grave importance considering the potential to contribute to short and long distance disease spread since citrus is vegetatively propagated. Therefore, the Texas Department of Agriculture (TDA) recently initiated new regulations requiring commercial and retail citrus nurseries in Texas to transition from traditional, open-field facilities to enclosed facilities with insect-resistant screens in order to prevent exposure of nursery trees to infective ACPs, and thereby mitigate the risk of nurseries serving as sources of CLas (https://texasagriculture.gov/RegulatoryPrograms/PlantQuality/Ci trusInformation.aspx). Nurseries with trees budded prior to enactment of the new regulation by the TDA in September 2012, so-called "grandfathered" nursery trees, were given a grace period for compliance for these trees. Whereas several nursery production facilities have complied with the new regulation, existing open or semi-open nurseries continue to pose a significant threat to the citrus industry as sources of CLas inoculum during this transitioning period. 
In order to investigate the possibility that existing open nurseries could be possible sources of spread of HLB, a systematic survey for HLB was conducted in a semi-open nursery located in South Texas in April 2014.

\section{SURVEYING FOR HLB IN A SEMI-OPEN NURSERY}

Study location and survey method. The semi-open citrus nursery facility (Fig. 1) surveyed for the study is located in the LRGV of south Texas (location concealed for confidentiality). The choice of the nursery was based on its location in an area with a high concentration of HLB detections in recent surveys conducted by the USDA-APHIS and the Texas Citrus Mutual. A census of citrus trees in the facility was provided by the manager of the nursery (Table 1). Based on this list, $5 \%$ of the total 1,800 potted nursery trees in the facility were sampled in a manner that each variety or cultivar was represented in the sample, and trees located towards the entrance of the facility were prioritized for sampling vs. trees located further inside the nursery (Fig. 1; Table 1). The rationale for this systematic sampling method was that infective ACPs carrying CLas and migrating from groves surrounding the nursery facility are more likely to alight and feed on trees proximal to the nursery entrance relative to trees located further inside the facility. Thus, the likelihood of finding an HLBinfected tree should, theoretically, be greater among trees located toward the facility entrance, with a disease gradient as one moves further inside the nursery. Regardless of the location, individual trees were inspected visually, and suspect trees identified based on symptoms of the disease (Fig. 2). Each selected tree was tagged with a unique identifier to retrace trees of interest, if necessary.

Sample collection. Four to six mature leaves with the intact petioles were collected from each tree sampled and placed into a 3.8-liter sealable Ziploc bag. Each sample bag was labeled with the sample identifier on the tree tag, and details of each sample (location, identification, cultivar, and sample number) were recorded. The samples were then transported immediately to the HLB diagnostic laboratory facility of the Texas A\&M University Kingsville-Citrus Center for testing. Sampled trees and adjacent trees on all sides were also inspected visually for the presence of ACP adults and nymphs.

\begin{tabular}{lcc}
\multicolumn{4}{c}{ TABLE 1} & \\
\multicolumn{1}{c}{$\begin{array}{c}\text { Provenance of samples collected from a semi-open } \\
\text { citrus nursery propagation facility in South Texas that }\end{array}$} \\
\multicolumn{1}{c}{ was surveyed for 'Candidatus Liberibacter asiaticus'. } \\
Citrus varieties/cultivar* & $\begin{array}{r}\text { Total number } \\
\text { of trees in } \\
\text { the nursery }\end{array}$ & $\begin{array}{c}\text { Number } \\
\text { of trees } \\
\text { sampled }\end{array}$ \\
\hline Ruby Red & 1 & 1 \\
Pomello & 22 & 1 \\
Blood Orange & 10 & 1 \\
Valencia & 52 & 2 \\
Marrs & 220 & 11 \\
N33 Navel & 358 & 18 \\
Everhard Navel & 152 & 8 \\
Pineapple Orange & 6 & 1 \\
Lima Mex & 3 & 1 \\
Thorny Mexican Lime & 3 & 1 \\
Thornless Mexican Lime & 222 & 11 \\
Ponderosa & 7 & 1 \\
Valley Lemon/Myers & 368 & 18 \\
Kumquat & 12 & 1 \\
Tangerine & 319 & 2 \\
Satsuma & 45 & 16 \\
\hline * Varietal/cultivar census as provided by the managers of the nursy
\end{tabular}

* Varietal/cultivar census as provided by the managers of the nursery.

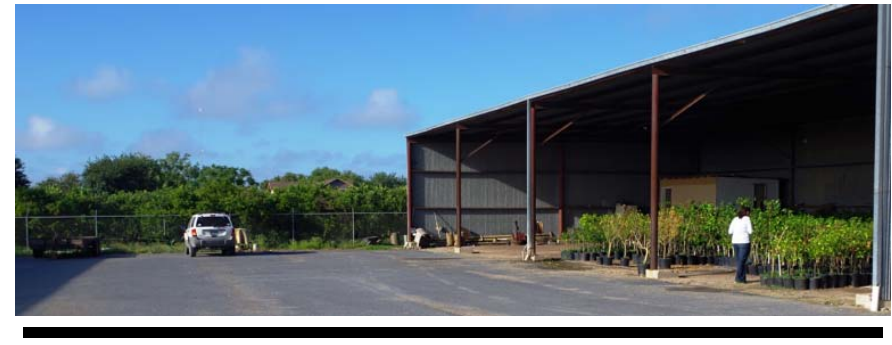

FIGURE 1

A semi-open, citrus propagation nursery facility located in the lower Rio Grande Valley of South Texas. Current estimates indicate that about 70,000 so-called "grandfathered" citrus nursery trees are located in several such nurseries across Texas, which are exempt from the requirement for production in enclosed, psyllid vector-proof, nursery facilities for management of Huanglongbing caused by Candidatus Liberibacter asiaticus. In a recent survey conducted by the Texas Citrus Mutual (Jon Dale, personal communication), several trees adjacent to the nursery facility (shown in this photo) tested positive for CLas using quantitative PCR assays.
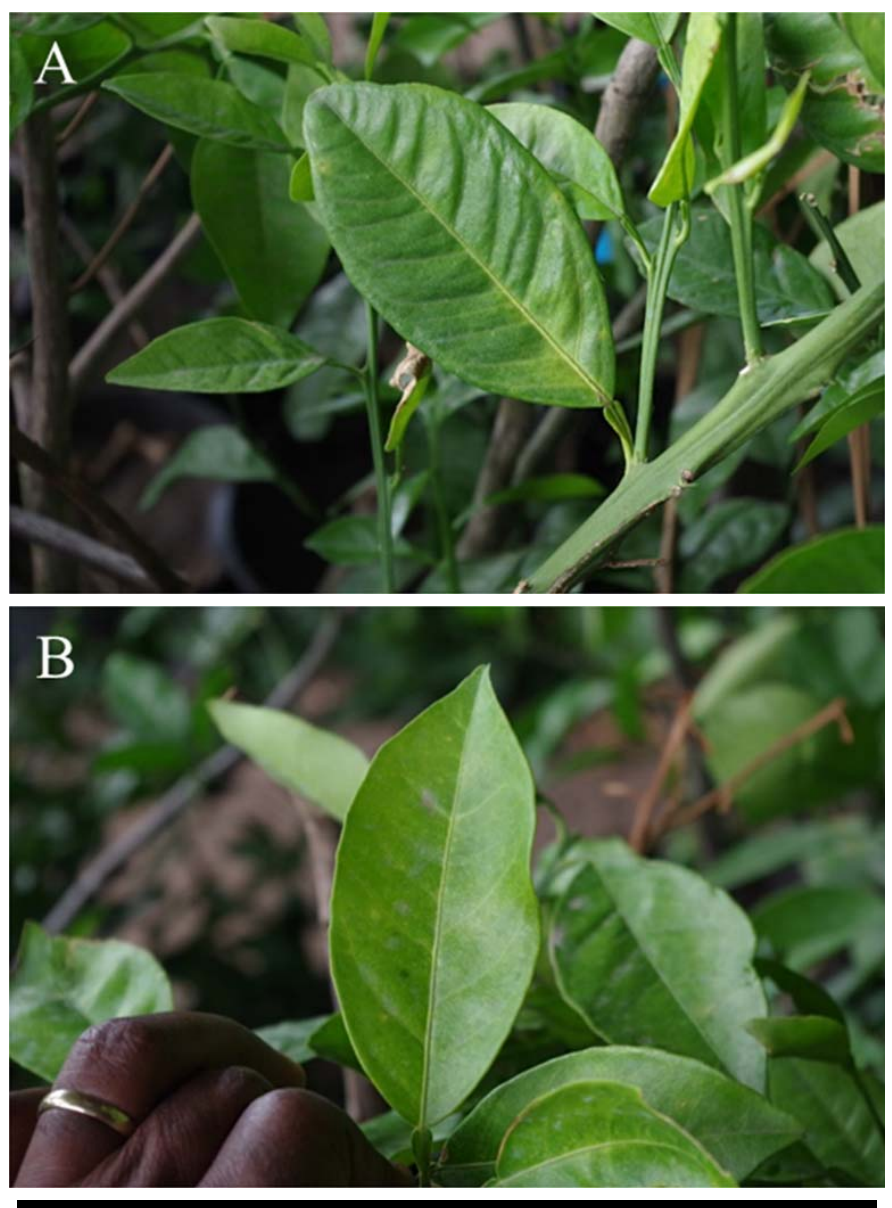

FIGURE 2

Symptoms of huanglongbing (HLB) on N33 navel orange samples collected from potted citrus plants in a semi-open citrus nursery facility in South Texas. Symptoms consist of raised and chlorotic veins and midrib; a blotchy, chlorotic mottle, especially at the base of the leaf; corky veins; a leathery feel to the leaf (A); and chlorosis of the vein and midrib with a mild mottle appearance $(\mathbf{B})$. 
DNA extraction. DNA extractions were made from the sampled leaves using the DNeasy Plant Mini Kit (Qiagen Inc., Valencia, CA) according to the manufacturer's protocol. Briefly, $200 \mathrm{mg}$ finely chopped leaf midribs or petioles from the sampled leaves were pulverized for 3 min with a Mini-Beadbeater-96 (Biospec Products Inc, Bartlesville, OK) in a $2 \mathrm{ml}$ lysing matrix A (MP Biomedicals, Santa Ana, CA) in a microcentrifuge tube in the appropriate extraction buffer. Genomic DNA was then eluted in $100 \mu \mathrm{l}$ nuclease-free water, and used directly in both a quantitative PCR assay and a conventional PCR assay.

Quantitative and conventional PCR assays and sequencing. DNA aliquots from each sample were subjected to a Taq-Man quantitative, multiplex, real-time PCR assay on a CFX96 Touch Real-Time PCR Detection System (Bio-Rad Laboratories, Inc., Hercules, CA) using probe-primer sets specific to CLas, CLam, and a plant cytochrome oxidase (COX)-based internal control treatment, as described by $\mathrm{Li}$ et al. (10). Amplification conditions consisted of an initial denaturation step at $95^{\circ} \mathrm{C}$ for $20 \mathrm{~s}$, followed by 40 cycles of $95^{\circ} \mathrm{C}$ for $10 \mathrm{~s}$ and $58^{\circ} \mathrm{C}$ for $40 \mathrm{~s}$. Asymptomatic plant DNA and a non-template water control (NTC) treatment were included in the quantitative PCR assays. The data were analyzed using the CFX Manager software. Samples that tested positive by quantitative PCR assay were confirmed to be infected by conventional PCR assay using a S1000 Thermal Cycler (BioRad Laboratories, Inc.) with two sets of primers targeting distinct loci of the CLas genome. The primer pair OI1/OI2c is capable of amplifying a $\sim 1,160 \mathrm{bp}$ DNA fragment specific to the $16 \mathrm{~S}$ ribosomal DNA (rDNA) sequences of CLas (8), while the primer pair A2/J5 amplifies a 703 bp fragment specific to the CLas ribosomal protein genes of $\beta$ operon (7). The $25 \mu$ reaction volume consisted of $2 \mu \mathrm{l}$ template DNA extract, $1 \mathrm{X}$ PCR reaction buffer, $1.25 \mu \mathrm{l} 50 \mathrm{mM} \mathrm{MgCl}_{2}, 0.5 \mu \mathrm{l} 10 \mathrm{mM}$ dNTP mix, $2.5 \mu \mathrm{l} 20$ $\mu \mathrm{M}$ OI1/OI2c or A2/J5 primer mix, and 2.5 U Platinum Taq DNA polymerase (Life Technologies Corp., Carlsbad, CA).

Amplification conditions consisted of an initial denaturation step at $95^{\circ} \mathrm{C}$ for $20 \mathrm{~s}$ followed by 25 cycles of $95^{\circ} \mathrm{C}$ for $10 \mathrm{~s}, 58^{\circ} \mathrm{C}$ for $30 \mathrm{~s}$ and $72^{\circ} \mathrm{C}$ for $60 \mathrm{~s}$. The amplified DNA fragments were resolved on a pre-stained $1 \%$ agarose gel. PCR-amplified bands of the expected size were gel-purified using a QIAquick Gel Extraction Kit (Qiagen Inc., Valencia, CA), and sequenced directly (MCLAB, San Francisco, CA). Derived sequences were inspected visually, edited, and subjected to BLASTn analysis (1) for homology and specific identification of the sequences.

\section{EVIDENCE OF CLAS IN SAMPLED NURSERY TREES}

Sample collection. A total of 94 samples from 16 citrus varieties were collected from the semi-open nursery facility (Table 1). This represented $5.2 \%$ of the citrus nursery trees at the facility. Based on the sampling scheme, about $50 \%$ of the samples were collected from trees located towards the entrance of the facility (Fig. 1). Although the trees were inspected visually for ACP vectors, no adult or juvenile ACPs were found on any of the trees surveyed.

CLas detection. Based on the quantitative PCR assays, 3 (3.2\%) of the 94 sampled trees tested positive for CLas with 23.8 to 27.9 cycle threshold $(\mathrm{Ct})$ values. The remaining 91 trees tested negative for CLas and CLam by quantitative PCR assay using a cut-off $\mathrm{Ct}$ value of 37. A breakdown of the HLB-positive samples revealed that two were derived from the sweet orange cultivar $\mathrm{N} 33$ Navel (Ct values of 27.5 and 27.9), and the third sample was from the sweet orange cultivar Marrs (Ct value of 23.8). However, diagnostic HLB symptoms consisting of raised and chlorotic veins and midrib, a blotchy chlorotic mottle at the base of the leaf, corky veins, and a leathery feel to the leaf were only apparent for one of the two CLas-positive N33 Navel orange trees (Fig. 2A). HLB-like symptoms on the second CLas-positive N33 Navel orange tree consisted of chlorosis of the vein and midrib, as well as very mild mottling (Fig. 2B). No symptoms were discernible on the CLas-positive Marrs sweet orange tree (data not shown).

The above results were also confirmed by conventional PCR assay. The primer pair A2/J5 yielded an $\sim 700 \mathrm{bp} \mathrm{DNA} \mathrm{product}$ from all three quantitative PCR-positive samples (Fig. 3A), while the primer pair OI1/OI2c amplified a $\sim 1,100 \mathrm{bp}$ product from each of the same samples (Fig. 3B). DNA fragments of the same sizes were amplified from a positive control sample, while no product was obtained from a negative control sample using both sets of primers (Fig. 3). Notably, all three CLas-positive trees were located in the front quarter of the nursery near the entrance.

Sequence analyses. Further confirmation of the PCR results was obtained by a multi-locus sequence analysis. After removing primer sequences and sequence artifacts, the 1,125 nucleotide (nt) sequence specific to the $16 \mathrm{~S}$ rDNA of one N33 Navel orange and the Marrs orange samples were subjected to BLASTn analysis. The sequences obtained from both HLB-positive samples (GenBank accession numbers KM224447-51) were specific to CLas and shared 97.5 to $99.9 \%$ nt identity among themselves and 97.6 to $100 \%$ nt identities with corresponding sequences of CLas strains gxpsy and psy62 (GenBank accession numbers CP004005 and CP001677, respectively). Similarly, the 654 nt sequences specific to the CLas ribosomal protein genes of $\beta$ operon obtained from the same samples (KM224452-56) were specific to CLas in the BLASTn analysis, and shared 99.5 to $100 \%$ nt identity among themselves and 99.6 to $100 \%$ nt identities with corresponding sequences of CLas strains gxpsy and psy62 (GenBank accession numbers CP004005 and CP001677, respectively). The results provide the first definitive evidence of the presence of CLas in nursery trees located in a semi-open citrus nursery in Texas.

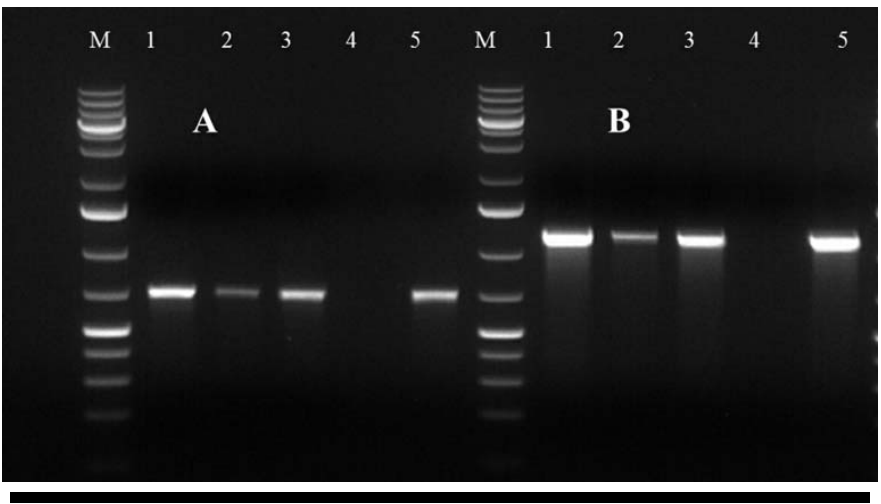

FIGURE 3

Agarose gel electrophoresis of amplified bands of DNA from a conventional PCR assay using Candidatus Liberibacter asiaticusspecific primers $(7,8)$. Primers A2/J5 produced a 703 bp fragment $(A)$, and primers OI1/OI2c yielded a 1,160 bp fragment (B). Panels A \& B: lanes $1 \& 2=$ N33 Navel sweet orange; 3 = Marrs sweet orange; $4=$ non-template water control sample; and $5=$ Candidatus Liberibacter asiaticus positive control sample. $\mathrm{M}=1 \mathrm{~kb}$ Plus DNA ladder (Fermentas). 


\section{DISCUSSION}

HLB constitutes a threat to sustainability of the citrus industry in the United States and several citrus-producing countries across the globe. So far, the disease has been reported in all major citrus producing areas of the world including the United States, China, and Brazil, with associated economic losses (2). All members of the Rutaceae are susceptible to HLB, and there is no known cure for the disease. Current HLB mitigation efforts consist of aggressive ACP vector control using a combination of chemical and biocontrol agents, identification and rouging of infected trees, and planting "clean" nursery trees (11).

Since the first detection of the disease in January 2012 (9), HLB has been found in several groves and residential sites throughout the LRGV of south Texas. Currently, Hildago and Cameron counties are under federal quarantine for HLB in order to prevent further spread of the disease in Texas. Besides this exclusion measure, an active, area-wide ACP management program is being implemented to target different life stages of the $\mathrm{ACP}$ vector of CLas. Growers and residential citrus owners are also being educated on the benefits of an aggressive ACP management plan that includes removal of HLB-infected trees. In spite of these efforts, recent results indicate an exponential increase in the number of HLB-positive trees, infected groves, as well as positive ACP populations across the LRGV (M. Sétamou, unpublished data). This has prompted concerns from citrus stakeholders that nurseries could be sources of disease spread given that a considerable number of nursery stocks are still propagated in open or semi-open facilities.

Although the TDA, in consultation with relevant stakeholders in the Texas citrus industry, initiated new regulations to prevent exposure of nursery stocks to infective migrant ACPs, trees budded prior to enactment of the new regulation, so-called "grandfathered" nursery trees, nurseries were given a grace period for compliance with the new regulation. Given the potential risk that such trees pose to the industry, the current study was conducted to determine the disease status of one of such "grandfathered" citrus nursery facility so that relevant agencies and stakeholders could make science-based management decisions. The results of this study showed conclusively that trees located in such a non-enclosed facility devoid of insect-resistant screens may pose a threat to the Texas citrus industry as a potential source of CLas. Although only $3.2 \%$ of the 94 sampled trees from the nursery tested positive for HLB, it is plausible that other trees in the lot may be infected since the 94 sampled trees represented only $5 \%$ of the trees in the facility investigated. It is also plausible that some CLas-negative trees in this nursery, and in similar facilities across Texas, may harbor undetectable titers of CLas. This is especially the case given the long period of incubation of the pathogen in the citrus host (5), and the fact that the trees may have been exposed to ACP infestation over a prolonged period.

Like all pathogens transmitted via vegetative plant propagules, nursery stocks represent a possible primary means of long distance spread of CLas from which new disease foci may be generated in citrus groves and residential sites. Interestingly, nursery plants were also implicated in the HLB pandemic experienced recently in the state of Florida (6). In that instance, the ornamental orange jasmine (Murraya paniculata), a host for both CLas and ACP (14), is thought to have contributed to rapid spread of the disease via nursery trade (6). Thus, efforts should be intensified to ensure that open and semi-open citrus nurseries in Texas are brought into compliance with new TDA regulations, and options explored for removal of the threat of exposed, "grandfathered" citrus nursery trees. This will benefit the Texas citrus industry in the long run since the number, location, and economic value of the "grandfathered" citrus nursery trees are limited relative to the size of the industry. This recommendation becomes more pertinent given that HLB-positive trees recently found in retail nurseries located in Harris, Fort Bend and Montgomery counties, TX, were reported to have been originally sourced from the same semi-open nursery facility investigated in this study. These finds represent the northern-most spread of the disease to date in Texas and has prompted the declaration of Harris, Fort Bend, and Montgomery counties as State quarantine areas for HLB in addition to Hildago, Cameron, and Willacy counties (https://mapsengine.google.com/16733486912059237704$05279445680642127559-4 / \mathrm{mapview} /$ ?authuser $=0$ ).

At the heart of successful surveillance for HLB in commercial groves, residential sites, and nursery facilities is an efficient and effective sampling protocol executed by well-trained HLB scouts in residential sites and nursery facilities. To facilitate this process, the USDA-APHIS has published a protocol to survey exclusionary facilities for the interstate movement of citrus and other rutaceous plants for planting from areas quarantined for citrus greening, Asian citrus psyllid, and citrus canker (http://www.aphis.usda.gov/plant health/plant pest info/citrus g reening/downloads/pdf files/CitrusSurveyProtocolExclusionaryFacilitiesInterstateMovement.pdf). The protocol emphasizes systematic sampling, and is particularly useful for sampling a large numbers of plants in a defined lot. A slight modification of the protocol is proposed to accommodate facilities such as the one surveyed in this study. Such modifications could include an evaluation of risk factors posed by the facility structure, such as proximity to neighboring groves, relative exposure of trees to outside sources of budwood for the nursery stock based on records kept by nursery managers, recognition of plausible HLB-like symptoms based on visual inspection, etc. Subset of trees in a nursery could then be assigned weights based on risk factors for sampling consideration. Given that risk factors might differ among facilities, peculiarities of each nursery would need to be taken into consideration for determining the best strategy to employ during surveillance efforts.

In conclusion, this study confirmed the presence of HLB and associated CLas in a semi-open citrus nursery facility in south Texas. Thus, this study underscores the significant threat "grandfathered" nursery trees may pose to the Texas citrus industry as possible avenues for long and short distance spread of HLB. Based on these finding, the TDA in consultation with relevant agencies and citrus stakeholders, has enacted a regulatory framework for high risk citrus nursery stock to include more rigorous conditions for compliance agreement and/or special permit for the retail, wholesale, re-wholesale or movement and commercial production of trees produced or maintained outside of enclosed structures.

\section{ACKNOWLEDGMENT}

This work was supported, in part, by a mini grant award from the Texas Citrus Producers Board. We are grateful to Ms. Jennifer Trevino (Texas Citrus Mutual, Mission, TX) and Ms. Kristina Loredo (Texas A\&M AgriLife Research, Weslaco, TX) for technical support, and to the proprietor of a semi-open nursery facility in South Texas for access to the property. We also thank Dr. John Jifon (Texas A\&M AgriLife Research, Weslaco, TX), Dr. Peter S. Ojiambo (North Carolina State University, Raleigh, NC), and Dr. Lindsey du Toit (Washington State University, Mount Vernon, WA) for critical review of the manuscript. 


\section{LITERATURE CITED}

1. Altschul, S. F., Gish, W., Miller, W., Myers, E. W., and Lipman, D. J. 1990. Basic local alignment search tool. J. Mol. Biol. 215:403-410.

2. Bove, J. 2006. Huanglongbing: A destructive, newly-emerging, centuryold disease of citrus. J. Plant Pathol. 88:7-37.

3. Deng, X., Lou, Z., Feng, Z., Li, H., Chen, J., and Civerolo, E. 2008. First report of 'Candidatus Liberibacter asiaticus' from Atalantia buxifolia in Guangdong, China. Plant Dis. 92:314.

4. Garnier, M., Eveillard, S. J., Cronje, P. R., Le Roux, H. F., and Bové, J. M. 2000. Genomic characterization of a liberibacter present in an ornamental rutaceous tree, Calodendrum capense, in the Western Cape province of South Africa. Proposal of 'Candidatus Liberibacter africanus subsp. capensis'. Int. J. Syst. Evol. Microbiol. 50:2119-2125.

5. Gottwald, T. R. 2010. Current epidemiological understanding of citrus huanglongbing. Annu. Rev. Phytopathol. 48:119-139.

6. Halbert, S. E., Manjunath, K. L., Ramadugu, C., and Lee, R. F. 2012. Incidence of huanglongbing-associated 'Candidatus Liberibacter asiaticus' in Diaphorina citri (Hemiptera: Psyllidae) collected from plants for sale in Florida. Fla. Entomol. 95:620-627.

7. Hocquellet, A., Toorawa, P., Bové, J. M., and Garnier, M. 1999. Detection and identification of the two Candidatus Liberibacter species associated with citrus huanglongbing by PCR amplification of ribosomal protein genes of the beta operon. Mol. Cell. Probes 13:373-379.
8. Jagoueix, S., Bové, J. M., and Garnier, M. 1996. PCR detection of the two Candidatus Liberibacter species associated with greening disease of citrus. Mol. Cell. Probes 10:43-50.

9. Kunta, M., Sétamou, M., Skaria, M., Li, W., Nakhla, M. K., and da Graça J. V. 2012. First report of citrus huanglongbing in Texas. Phytopathology 102:S4.66

10. Li, W., Hartung, J. S., and Levy. L. 2006. Quantitative real-time PCR for detection and identification of Candidatus Liberibacter species associated with citrus huanglongbing. J. Microbiol. Methods 66:104-115.

11. National Research Council. 2010. Strategic Planning for the Florida Citrus Industry: Addressing Citrus Greening. The National Academies Press, Washington, DC.

12. Planet, P., Jagouxie, S., Bové, J. M., and Garnier, M. 1995. Detection and characterization of the African citrus greening Liberibacter by amplification, cloning and sequencing of the rplKAJL-ropBC operon. Curr. Microbiol. 30:137-141.

13. Teixeira, D. A., Eveillard, S., Martins, E. C., Jesus, W. C., Jr., Yamamoto, P. T., Lopes, S. A., Bassanezi, R. B., Ayres, A. J., Saillard, C., and Bové, J. M. 2005. Citrus huanglongbing in São Paulo State, Brazil: PCR detection of the 'Candidatus Liberibacter' species associated with the disease. Mol. Cell. Probes 19:173-179.

14. Zhou, L. J., Gabriel, D. W., Duan, Y. P., Halbert, S. E., and Dixon, W. N. 2007. First report of dodder transmission of huanglongbing from naturally infected Murraya paniculata to citrus. Plant Dis. 91:227. 